\title{
Justice for climate loss and damage
}

\author{
Ivo Wallimann-Helmer ${ }^{1}$
}

Received: 5 September 2014 / Accepted: 9 August 2015 / Published online: 29 August 2015

(C) Springer Science+Business Media Dordrecht 2015

\begin{abstract}
This paper suggests a way to elaborate the ethical implications of the Warsaw International Mechanism (WIM) as decided at COP 19 from the perspective of justice. It advocates three proposals. First, in order to fully understand the responsibilities and liabilities implied in the WIM, adaptation needs to be distinguished from loss and damage (L\&D) on the basis of the different goals which should be attributed to adaptation and to L\&D approaches. Second, the primary concern of the WIM should be compensatory justice. In case of climate L\&D, three aspects of compensatory justice should be kept separate: corrective liability, remedial responsibility, and with regard to the resources available, fair remedy. Third, it is crucial to distinguish between recoverable damage and irrecoverable or at least not fully recoverable loss. This distinction is crucial because it informs the principles of fair remedy and because damage and loss may differ in their relevance for the stability and functioning of a human system.
\end{abstract}
Abbreviations
L\&D Loss and Damage
WIM Warsaw International Mechanism

\section{Introduction}

At their 19th conference in Warsaw (COP 19), the parties to the UNFCCC established the Warsaw International Mechanism (WIM) to "address loss and damage associated with impacts of climate change, including extreme events and slow onset events, in developing countries that are particularly vulnerable to the adverse effects of climate change (...)". The WIM should

This article is part of a Special Issue on "Climate Justice in Interdisciplinary Research" edited by Christian Huggel, Markus Ohndorf, Dominic Roser, and Ivo Wallimann-Helmer.

This paper is linked to the following contribution of this special issue: Huggel et al., doi:10.1007/s10584-015-1441-z

Ivo Wallimann-Helmer

wallimann@philos.uzh.ch; http:/www.ethik.uzh.ch/ufsp/ma/ivowallimannhelmer_en.html

1 Research Priority Program for Ethics, University of Zurich, Zollikerstrasse 117, 8008 Zurich, Switzerland 
promote "the implementation of approaches to address loss and damage (...) in a comprehensive, integrated and coherent manner (...)" (UNFCCC 2014). In light of Working Group II's contribution to the Fifth Assessment Report of the Intergovernmental Panel on Climate Change, the WIM is a much needed political step forward (IPCC 2014). However, it remains an open question whether developed countries should "provide developing country Parties with finance, technology and capacity-building" (UNFCCC 2014) due to considerations of liability or due to other kinds of responsibility.

This paper makes an attempt to answer this question by elaborating the ethical implications of the WIM from the perspective of climate justice and normative justice research more generally. It advocates three proposals. First, in order to fully understand the responsibilities and liabilities implied in the WIM, a clear distinction between adaptation and loss and damage (L\&D) must be defined. The paper suggests distinguishing between adaptation and L\&D on the basis of the different goals which should be attributed to adaptation and to L\&D approaches. Second, defining the distinction between adaption and L\&D on the basis of these goals reveals that the primary concern of the WIM should be compensatory justice. Closer examination of the different aspects of compensatory justice shows that the questions of how to distribute remedial responsibilities and how, given the resources available, to fairly remedy L\&D are more significant than the attribution of corrective liabilities. Third, the paper suggests that it is crucial to distinguish between recoverable damage and irrecoverable or at least not fully recoverable loss. This distinction is crucial because it informs the principles of how to most fairly remedy L\&D and because damage and loss may differ in their relevance for the stability and functioning of a human system.

\section{Adaptation vs. loss \& damage}

The WIM has been established "acknowledging that loss and damage associated with the adverse effects of climate change includes, and in some cases involves more than, that which can be reduced by adaptation, (...)" (UNFCCC 2014). In accordance with the L\&D literature, this acknowledgement states that at least some of the adverse effects of climate change cannot be addressed by adaptation measures (cf. Nishat et al. 2013; Warner and van der Geest 2013). It is these kinds of climate impacts which make the WIM a mechanism that demands approaches distinct from adaptation measures. Consequently, the WIM requires a different assignment of responsibilities and liabilities for research, finance, implementation and assistance than for adaptation. Since these responsibilities and liabilities define the duties of justice implied in the WIM, elaborating its ethical implications requires a clear line to be drawn between adaptation and L\&D. However, three of the most obvious ways to distinguish between adaptation and L\&D, often mentioned in both policy discussions and the L\&D literature, turn out to be more unclear than at first appears. ${ }^{1}$

\footnotetext{
${ }^{1}$ I agree with an anonymous reviewer that a fourth obvious way to distinguish between adaptation and L\&D would be to differentiate them by the goals of both kinds of approaches. For instance, one could argue that whilst the goal of adaptation is to allow those facing climate impacts to cope with them, the goal of L\&D approaches is to compensate for climate impacts that occur. However, although such a distinction seems straightforward and seems to eliminate the difficulties discussed in the following, I do not agree that no argument is needed to show why distinguishing adaptation from L\&D by their different goals is the most plausible approach. Furthermore, even though it might be intuitively clear how to define these different goals, these definitions need justification as well. The following discussion aims to provide both.
} 
First, both adaptation and L\&D approaches mean that a human system reacts to cope with existing or anticipated climate impacts. This makes it difficult to distinguish between adaptation and L\&D by differentiating whether or not approaches are concerned with L\&D. Generally speaking, adaptation means that a human or natural system adjusts to changing conditions. In the case of climate change, this can be due not only to more intense or more frequent disastrous weather events but also due to slow onset and gradual climate events which affect the stability and functioning of a system (Stone et al. 2013). Adaptation, therefore, is initiated by impacts and, in the case of human systems, anticipated impacts on the system. In case of human systems, these impacts are most often, if not exclusively, L\&D threatening valued objectives. Thus, what mainly motivates the adaptation of human systems is existing or anticipated L\&D. Since L\&D is also the driver for adaptation, it becomes difficult to see how to draw the line between adaptation measures and L\&D approaches by relying on whether they are concerned with L\&D or not. Existing or anticipated L\&D not only motivates L\&D measures but also drives adaptation efforts. In consequence, a clear distinction between responsibilities and liabilities exclusively relevant for the WIM and those relevant for adaptation is not possible either.

Second, since the driver for both adaptation efforts and L\&D measures is existing or anticipated L\&D, the goal of both kinds of approaches is to diminish risks, even if different kinds of risks. Although the next section suggests that the primary concern of the WIM should be how to appropriately remedy L\&D once it has occurred, L\&D measures must be established long before L\&D actually materializes. The fact that the intensity and frequency of disastrous weather events increases does not mean that L\&D is permanent. There is only a higher probability that $L \& D$ will occur. Hence, investing in L\&D measures means that a human system prepares to cope with the existing or anticipated risk of negative effects of L\&D occurring. This makes it difficult to distinguish between adaptation and L\&D by arguing that adaptation measures fundamentally differ in their nature from L\&D approaches. It is not only adaptation measures which are prospective in nature; L\&D measures are not solely retrospective in nature, only concerned with how to remedy L\&D once it has occurred. ${ }^{2}$ Hence, it becomes difficult to distinguish responsibilities and liabilities exclusively relevant for the WIM from duties to assist in adaptation by arguing that their focus is fundamentally different. The goal of both adaptation measures and L\&D approaches is diminishing risks. But while adaptation efforts aim to diminish the risk of the occurrence of $L \& D, L \& D$ approaches aim at diminishing potential negative effects of L\&D on a human system once L\&D has occurred.

This reveals why not only adaptation measures but also L\&D approaches cover risk management. But a third difficulty in distinguishing L\&D from adaptation is that it is not evident which approaches to risk management fall within the category of adaptation and which are exclusively relevant to addressing L\&D. A common taxonomy for distinguishing different approaches to risk management illuminates this point, the distinction between risk reduction, risk retention, and risk transfer (e.g. Wrathall et al. 2013). Risk reduction aims at reducing the risk of climate impacts. Approaches in this category include building dykes or installing early warning systems. Risk retention consists in building resilience such as social protection programs to enhance the ability of individuals and communities to cope with extreme weather events. Risk transfer involves transmitting risks from individuals or organizations to an insurer or to the community as a whole. It includes, for example, insurance for damage to crops due to

${ }^{2}$ I would like to thank Peter Burnell and an anonymous reviewer for suggesting this possible distinction between adaptation and $L \& D$. 
hazardous weather events. All these approaches can equally well be understood as L\&D approaches or as adaptation measures. Their development means that a human system is adjusting to the existing or anticipated risks of adverse effects of climate change. Therefore, the responsibilities and liabilities relevant for $L \& D$ cannot be distinguished from those for adaptation simply by relying on different kinds of approaches to risk management. A clear distinction between adaptation and $L \& D$ is needed first.

Hence, it remains necessary to find a way to clearly separate the responsibilities and liabilities of adaptation from those of L\&D if we are to analyze the implications of justice in the WIM. As already mentioned, the risks adaptation measures aim to diminish differ from those L\&D approaches aim to minimize. This makes it possible to draw a distinction between L\&D and adaptation in terms of the different kinds of risk both approaches aim to diminish. One possible way to distinguish different kinds of risk is proposed by Dow et al. (2013). According to their conception, some risks are perceived as acceptable, others as tolerable, and still others as intolerable, depending on the adaptive capacity of a human system. The limits of adaptation are reached when risks become intolerable. Intolerable risks arise when a human system is not able to adapt to anticipated negative climate impacts. Hence, according to this conception, what distinguishes adaptation measures from L\&D approaches is the kinds of risk they cover. However, this solution makes it necessary to bring the goals of adaptation measures and of L\&D approaches more closely into focus.

Following Dow et al. (2013), the limits of adaptation are reached when climate risks become intolerable. As a consequence of this conception, the goal of adaptation measures should be to keep the risk of climate impacts within the range of acceptable or tolerable risk. Adaptation thus refers to those measures which are perceived as having the potential to keep climate risks within this range of acceptable or tolerable risk. Put simply, since acceptable or tolerable risks are those which any individual, organization or community would perceive as risks which can be approved, the goal of adaptation must be to prevent L\&D. For example, this would be the case when dykes are built which render risk of crop failure despite high river flow acceptable. Another example would be a risk retention program which subsidizes the socioeconomically disadvantaged to take individual precautionary measures to reduce the risk of bush-fire damage to a tolerable level.

Following on from this definition of the goal of adaptation measures, if the two kinds of approaches are to be distinguished, the goal of L\&D approaches cannot be to keep risk of negative climate impacts within an acceptable or tolerable range. Otherwise, both kinds of approaches would coincide. Following Dow et al. (2013), the limits of adaptation are reached when a human system is no longer able to secure valued objectives. Hence, in contrast to adaptation, the goal of L\&D approaches cannot be conceived as diminishing the risk of the occurrence of climate impacts. Since the limits of adaptation are reached when a human system is no longer able to keep the risk of climate impacts in an acceptable or tolerable range, L\&D approaches must be those which allow a human system to cope with the potential negative effects of L\&D. Consequently, the goal of L\&D approaches can be defined as diminishing the potential negative effects of L\&D occurring on a human system. This can mean, for example, that early warning systems are built not in the belief that they can prevent deaths altogether but to minimize their number. Similarly, in the case of $L \& D$, the purpose of risk transfer cannot be to prevent impacts but to provide appropriate support for those harmed. However, L\&D can also occur when adaptation measures fail. L\&D approaches should also cover these kinds of risk for negative climate impacts. Here again, risk transfer systems can become relevant, for instance following a breach in a dyke. 
Defining the distinction between adaptation and L\&D approaches by their differing goals allows the three difficulties identified above to be addressed. The goal of adaptation approaches is to keep the risk of climate impacts within an acceptable or tolerable range. The goal of L\&D approaches is to diminish the potential negative effects of L\&D occurring on a human system. First, this distinction does not rely on the question whether or not approaches are concerned with $L \& D$, because $L \& D$ is understood as the main driver for establishing measures for both kinds of goals. Second, since the distinction focuses on the goal of the approaches, it is no longer necessary to attempt to distinguish between adaptation and L\&D measures by whether they are prospective or retrospective in their nature. Third, it allows a categorization of risk management approaches as either adaptation or L\&D measures by their perceived capacity to keep risk in an acceptable or tolerable range.

\section{Some implications of justice}

The last section suggested distinguishing adaptation from L\&D by the different goals of the respective approaches. The goal of adaptation approaches should be to keep risk of climate impacts in an acceptable or tolerable range; the goal of L\&D approaches should be to diminish the potential negative effects of $L \& D$ occurring on a human system, be it due to intolerable risks or as a consequence of impacts occurring despite adaptation measures. From the viewpoint of justice, this distinction has several implications for responsibilities and liabilities. These implications include the question of how to remedy L\&D and hence compensatory justice. Closer examination of the different aspects of compensatory justice reveals that there are good reasons why the WIM should be less concerned with questions of liability for L\&D and more with how to most efficiently, effectively and fairly minimize the negative effects of L\&D on a human system.

According to the distinction suggested between adaptation and $L \& D$, the main concern of L\&D approaches should be how to diminish the potential negative effects of L\&D occurring on a human system. This means that appropriate risk management approaches for L\&D should foster schemes to minimize the amount of L\&D that actually occurs and, when L\&D has occurred, to remedy negative impacts. This opens the highly contested field of compensatory justice. Compensatory justice covers three different aspects which are often not clearly separated (Miller 2007; Blum and Lockwood 2012): corrective liability, remedial responsibility, and fair remedy. ${ }^{3}$ First, corrective liability in a strict sense demands that those who caused or contributed to L\&D are liable to remedy it. Second, in many cases the party causing or the parties contributing to $L \& D$ are able to remedy it. If this is not the case, and especially if L\&D is severe, other parties can be seen as responsible for subsidizing remedy. In this case, it seems to be more appropriate to separate corrective liabilities from remedial responsibilities. Third, if resources for remedy are scarce or if approaches available do not allow to fully recover injured parties, it is important to consider how to most fairly carry out remedy. In case of climaterelated $L \& D$, there are good reasons why these three aspects of compensatory justice should be assessed separately.

To see why this is the case, a preliminary general observation is in order. Climate change is most often only one but not the single cause of L\&D. Thus, detecting that a human system

\footnotetext{
${ }^{3}$ These labels are introduced here to give the three different aspects of compensatory justice a name. However, as they stand, they are not common in normative research on compensatory justice.
} 
changes due to an existing or anticipated risk of climate impacts is one thing, but to attribute these changes and L\&D undoubtedly to climate change is quite another (Stone et al. 2013; Visser et al. 2014). From the perspective of compensatory justice, this observation is highly relevant, since the vulnerability of a human system or of individuals is often increased not only due to changing climatic conditions. Vulnerability is also due to socio-economic disadvantage. For example, having fewer material resources makes it more difficult to invest in private safety measures. In the case of a disaster, a more fragile health care system provides less efficient and suitable assistance.

From the perspective of compensatory justice, it is an important question whether these disadvantages are fair or not. At the national level, the answer to this question depends on whether a country distributes its resources in a just way and non-discriminatorily invests in appropriate health care infrastructure. On a global scale, these disadvantages raise the questions of whether the global distribution of resources is just and in what way the global economic arrangements contribute to unjustified vulnerability in some parts of the world rather than others. As with all considerations of climate justice, a fully-fledged analysis of the justice implications of the WIM cannot be an isolated task but must take into account other justice considerations as well (Caney 2012). However, such an analysis would be far beyond the scope of this paper. ${ }^{4}$

These considerations reveal that the question of corrective liability for L\&D concerns not only climate change. Liability also covers the question of who unfairly contributed to the socio-economic conditions that increase vulnerability to climate L\&D. On a global scale, this means that unfair disadvantage in resources and economic arrangements would have to be compensated by those countries liable and benefitting unfairly from them. At the national level, inappropriate infrastructure to deal with $L \& D$ can be seen to be the responsibility of the government concerned but not the global community. Disentangling these different socioeconomic issues from vulnerability exclusively increased by climate change would be needed to appropriately assign corrective liabilities only relevant for climate-related L\&D.

The issue of disentangling becomes even more complex when considering a second general observation. Not all climate variability is anthropogenic. Although concerns of justice can also become relevant in the case of L\&D caused by natural climate variability, only in the case of anthropogenic climate change demands for compensatory justice vindicate the assertion of corrective liabilities. For instance, with regard to anthropogenic climate change, it seems plausible to argue that those who created the mess should tidy it up; that is to say, they should appropriately compensate the victims (Shue 1999). In the case of natural climate variability, in contrast, such an argument is not possible. No-one can be blamed for having caused the L\&D in question (Huggel et al. 2013). Hence, in the case of natural climate variability, it seems more plausible to argue that those who are best suited to do so should assist, irrespective of how much they have contributed to climate change (c.f. Page 2008; Caney 2010).

The challenge of disentangling natural from anthropogenic climate variability particularly concerns the first aspect of compensatory justice, corrective liability. In the case of L\&D, corrective liability covers the questions of who caused or contributed to the risk of negative climate impacts and hence is liable to contribute to subsidizing appropriate measures. This

\footnotetext{
${ }^{4}$ Since the parties at COP 19 established the WIM to address L\&D especially "in developing countries that are particularly vulnerable to the adverse effects of climate change (...)" (UNFCCC 2014) considerations concerning global social-economic injustice could be understood as one of the background assumptions for this mechanism.
} 
aspect concerns those principles of climate justice which, in line with international climate politics, maintain that countries historically or actually contributing more to anthropogenic climate change are liable for shouldering heavier burdens than those countries that did or do not (polluter-pays principles). ${ }^{5}$ These principles justify the distribution of burdens on the basis of past or current man-made emissions. Determining the fair size of burdens in counteracting climate change depends on the fraction of climate variability and resultant L\&D that can be attributed to anthropogenic emissions. Consequently, the ideal implementation of these principles demands rigorous scientific evidence concerning the attribution of L\&D to anthropogenic climate change. ${ }^{6}$

The case is quite different with regard to the second aspect of compensatory justice, namely the distribution of remedial responsibilities irrespective of the contribution to L\&D. Remedial responsibilities apply to principles of climate justice which justify a distribution of burdens according to economic, scientific or technological capacity (ability-to-pay principles). These principles do not rely directly on past or current man-made emissions. Thus, what is relevant to assigning responsibilities for burdens is solely the fact that hazardous climate or weather events in conjunction with L\&D occur or that their risk can be predicted with sufficient certainty by climate modeling. But attribution of climate impacts to anthropogenic emissions is not essential. Indeed, this is not to say that polluter-pays principles are irrelevant and should be dismissed. Neither does it mean that principles relying on past or current emissions should not be balanced with ability-to-pay principles. ${ }^{7}$ But in light of the distinction between adaptation and L\&D proposed here, these observations provide at least two reasons why the WIM should prioritize the question of how best to subsidize and implement L\&D measures and why the question of how most appropriately to assign corrective liabilities exclusively relevant for L\&D occurring due to anthropogenic climate change should be of secondary concern.

First, as argued in the previous section, L\&D approaches are prospective in nature. A human system must be prepared to cope adequately with L\&D occurring. This means that L\&D measures must be established before L\&D actually occurs. As a consequence, it becomes difficult, if not impossible, to establish and maintain mechanisms which exclusively manage anthropogenic climate change but not L\&D due to natural climate variability while disregarding increased vulnerability because of unfair global or national socio-economic inequality. Once established, L\&D approaches diminish the potential negative effects of L\&D on a human system irrespective of whether they are induced by anthropogenic or natural climate variability and whether increased vulnerability is due to socio-economic unfairness or climate change. Second, since L\&D is often a severe threat to the stability and functioning of a human system, it seems to be inappropriate to subsidize L\&D measures only to the point at which it can be proven that the risk of L\&D or L\&D occurring are due to anthropogenic climate change. Therefore, restricting responsibilities to subsidize L\&D approaches to corrective liability for climate related L\&D seems to be inappropriate. ${ }^{8}$

\footnotetext{
${ }^{5}$ The literature on polluter-pays principles and their relation to historical justice is a long-standing concern in climate ethics. Due to space limits, however, it is not possible to discuss these issues in more detail here. For a very helpful collection of essential essays, consider Gardiner et al. (2010).

${ }^{6}$ For a more detailed explanation of the three different scientific approaches mentioned here and in the following paragraph see the tandem paper to this article by Huggel et al. (2015).

${ }^{7}$ For further discussion of these issues see for example Vanderheiden (2009).

${ }^{8}$ For a more theoretical argument to similar conclusions see Meyer and Roser (2010).
} 
In consequence, according to the distinction between adaptation and L\&D proposed here, there are good reasons why the primary concern of the WIM should be the question of who is best able to subsidize L\&D measures. This concern is especially important with regard to (but not restricted to) ability-to-pay principles. According to these principles, countries better capable of helping diminish the potential negative effects of L\&D on a human system have a duty to contribute more to their solutions. This can be due to superior economic power, improved scientific or technological capacity. However, only focusing on this aspect of compensatory justice for L\&D and dismissing the third aspect of compensatory justice; the aspect of fair remedy would be devastating. It would be devastating because the goal of L\&D approaches is not to prevent the risk of L\&D altogether but to diminish the potential negative effects of L\&D occurring on a human system. Therefore, given the resources available, it becomes important to be clear about the fair way to remedy L\&D.

The question of how to fairly remedy L\&D once it has occurred involves two intertwined but separate issues. The first issue involves considerations of efficiency and effectiveness: how the negative effects of climate change on a human system can be optimally minimized. The second issue concerns how to fairly remedy climate impacts: L\&D needs either to be appropriately settled or, ideally, the L\&D should be recovered completely. Whilst the first issue is more concerned with technical, scientific and managerial challenges, from the perspective of compensatory justice the second issue is most essential. What, in the case of climate $L \& D$, fair remedy means and under what conditions full recovery of $L \& D$ can legitimately be deemed possible is the central concern of the next section. It analyzes the implications of fair remedy and how concerns of fairness should be balanced with considerations of efficiency and effectiveness in more detail.

\section{Two kinds of climate impacts}

As argued above, dismissing the third aspect of compensatory justice; fair remedy, would be devastating. With regard to compensatory justice it is an important question how to fairly remedy climate impacts. This is for three reasons. First, a fully fair solution to remedy L\&D cannot be found before it is clear what, given the resources available, would be the most fair way to remedy climate impacts. From the perspective of compensatory justice, this means that, prior to the question of how to distribute remedial responsibilities, it is necessary to clarify what remedial measures actually deliver fairness when L\&D has occurred. Second, considerations concerning fair remedy are paramount, because without taking them into account any approach to L\&D, however efficient and effective it may be, may do so in an unfair way. Third, without taking concerns of fair remedy into account, there is a risk that remedial principles demand too much or, more probably, not enough from those correctively liable or remedially responsible to subsidize the measures to be taken.

One of the reasons why there is a danger that L\&D approaches do not fully meet the demands of fair remedy is that climate impacts are most often monetized. Reports on hazardous weather events often summarize climate impacts in terms of the monetary costs of redressing L\&D. In many instances, arguments about which steps should be taken to combat climate impacts use cost-benefit calculations. Certainly, all these calculations are relevant to evaluating economic detriment and deciding the most efficient or effective responses to L\&D in financial terms. An economic analysis of the adverse effects of climate 
change, however, tends to ignore the fact that not all L\&D is quantifiable in monetary terms. It is these kinds of impacts which bear the danger that L\&D approaches do not fully meet the demands of fair remedy.

To understand why this is the case, it proves helpful to consider the general meaning of just compensation from a different angle than the three aspects of compensatory justice introduced so far. In the case of any kind of injury to a person's livelihood or assets, compensatory justice demands that a person is made as well off as he or she was before (Goodin 1989). If someone steals someone else's car, just compensation demands its return to its rightful owner. Similarly, damaging a borrowed car implies that one has to pay for the repairs needed or to buy a new car. Ideally speaking, just compensation means restoring the status quo ante, the status before a disadvantage has been inflicted. The situation of the injured party should be recovered; the L\&D suffered should be neutralized.

In the case of monetizable harm, this seems to be uncomplicated. Impacts on economic assets can be recovered simply by paying enough money to restore the status quo ante. This kind of compensation is what Goodin (1989) calls means-replacing compensation. Paying an appropriate amount of money for economic deprivation replaces the means lost and allows injured parties to pursue the same valued objectives as before. In the case of non-monetizable harm, however, such replacement of means is not or at least not fully possible. A crashed car which one inherited from one's parents cannot be replaced by simply paying enough money or buying another car of the same model. The memories attached to such a car are not, or at least not fully, monetizable. But paying money for a new car to restitute mobility and at the same time providing the injured individual with some kind of substitute for the memories attached to the crashed car might be sufficient. The aim of this kind of remedial action is not only to replace the means vanished but to assist injured individuals to revise their valued objectives. It assists an injured individual to feel subjectively as well off as before. ${ }^{9}$ Goodin (1989) calls this kind of compensation ends-displacing compensation, because it rectifies by assisting the revision of valued objectives. ${ }^{10}$

Ends-displacing compensation becomes most pertinent with regard to non-monetizable or not fully monetizable climate impacts. Since these kinds of impacts cannot be fully recovered in monetary terms, appropriate L\&D approaches must assist those facing these impacts to revise their valued objectives. For instance, in some regions, climate change diminishes fish stock, which has an impact on traditional fishery (UNFCCC 2013). In Alaska, coastal erosion and flooding due to longer sea-ice summers has forced many coastal and riparian villages to relocate (Bronen 2013). Most drastically, sea-level rise potentially makes it necessary that the whole people of a low island state must leave its home (IPCC 2014). In all three cases, not only are economic costs involved but also further non-monetizable negative impacts.

According to a range of normative theorists, these three cases vindicate demands of justice. A community that needs to find another way of fishing not only loses in economic resources; it also loses part of its cultural identity (Heyward 2014). Relocating a village is not only economically costly but also means that attachment to place is lost, which can be of major

\footnotetext{
${ }^{9}$ This claim faces two challenges which cannot be discussed here. First, assisting someone to revise his valued objectives readily tends to be overly paternalistic since helping changing objectives involves directives by those who assist. Second, whilst the costs of monetizable L\&D are clearly restricted by the amount of money lost in case of revising valued objectives the limit for resources to be spent for assistance is not as clear-cut as in the first case. I would like to thank an anonymous reviewer for mentioning both these concerns.

${ }^{10} \mathrm{I}$ am heavily indebted to Edward Page for mentioning Goodin's distinction between these two kinds of just compensation.
} 
importance for a village's or a specific individual's self-understanding (Bell 2004; de Shalit 2011). Without appropriate international regulations for climate refugees, the peoples of low island states not only lose their homelands but also their right to political self-determination (Byravan and Rajan 2010; Zellentin 2010). Thus, L\&D measures cannot remedy in a fair way in all cases if they only redress economic deprivation. In the case of non-monetizable or not fully monetizable climate impacts, L\&D approaches must also provide transition to different ways of livelihood, economic subsistence, cultural heritage, or political organization.

Hence, it seems that the WIM covers two different kinds of negative climate impacts. On the one hand, there are the climate impacts which allow means to be recovered in such a way that those harmed are able to pursue the same ends as before. This category of climate impacts includes all those adverse effects of climate change which can be restored completely without any or only marginal impact on livelihood, economic subsistence, cultural heritage, or political organization. On the other hand, there are those climate impacts that require changes in livelihood, kind of economic subsistence, cultural heritage, or political organization to be appropriately remedied. This category of impacts thus makes social transition an essential part of L\&D approaches, since it demands displacement of valued objectives. Therefore, the distinction often used in L\&D literature and some UNFCCC documents between recoverable damages and irrecoverable losses becomes pertinent from the perspective of compensatory justice (e.g. UNFCCC 2012; Nishat et al. 2013). Recoverable damages are those impacts that can be compensated by appropriate payments or other kinds of redistribution of assets. Irrecoverable losses, in contrast, make a displacement of valued objectives necessary.

These considerations suggest how to frame justice principles relevant for fair remedy and how they must be balanced with issues of efficiency and effectiveness. In cases of recoverable damage, the relevant principle of fair remedy is straightforward. Resources must be distributed to recover climate damages as fully as feasible for as many inflicted parties as possible. However, since resources to recover damages might be scarce and since due to socio-economic inequalities capacities for self-recovery can be distributed unequally, such a principle should have a constraint built in to prioritize those more disadvantaged (Blum and Lockwood 2012). In cases of irrecoverable or not fully recoverable loss, in contrast, the appropriate principles of fair remedy will vary according to the loss at issue. Other principles of fair remedy are more appropriate, depending on whether livelihood, economic subsistence, cultural heritage, or political organization is at stake. In neither kind of case will demands concerning efficiency and effectiveness necessarily coincide with demands of fairness. For instance, using approaches to L\&D neglecting inequalities in socio-economic status in the name of efficiency and effectiveness undermines their legitimacy. Similarly, investing the resources available efficiently and effectively but according to the wrong principle of fair remedy must be deemed unfair as well.

Moreover, although it might seem that climate loss should be dealt with as a primary concern, to argue for a strict priority of climate loss over climate damage is problematic. Losses seem to be more of a threat to a human system since they demand social transitions, changing how a human system remains stable and functioning, with all the consequent longlasting social and economic costs involved. However, in light of the overall economic costs of climate impacts on a human system, some losses might be trivial. ${ }^{11}$ Losing a car inherited from one's parents due to an extreme weather event might be unimportant in light of the millions of Swiss francs of recoverable assets damaged. Depending on the scale of means impaired due to

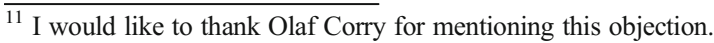


an extreme weather event, this damage can become more severe than all the small nonmonetizable losses single individuals face. These losses might have no or scarcely any bearing on the stability and functioning of a human system. Hence, climate loss has more weight than climate damage only when it involves a significant threat to the stability and functioning of a human system. In all other cases, climate damage and approaches to minimize its impacts are of primary concern.

As a consequence, it seems that the WIM should provide mechanisms for a case-by-case assessment of the L\&D faced by different communities due to different weather or slow onset and gradual climate events. How these mechanisms should be characterized must remain an open question for now. They could be conceived as some kind of application program for funding L\&D approaches to establish fair schemes of remedy. They could also be part of an adjusted system of international law allowing affected communities to claim fair remedy for L\&D. ${ }^{12}$ Whatever such mechanisms to implement the WIM should look like, from the viewpoint of compensatory justice it is crucial to facilitate the choice of appropriate principles of fair remedy and to balance the weight of loss with the weight of damage and their respective approaches suitably.

\section{Conclusion}

The aim of this paper was to elaborate the implications of justice in the WIM as decided upon by the parties in Warsaw at COP 19. In so doing, it proposed three crucial distinctions. First, it proposed that the goal of adaptation approaches should be conceived as keeping the risk of climate impacts within an acceptable or tolerable range. The goal of L\&D approaches, in contrast, seems to be better described as diminishing the potential negative effects of L\&D occurring on a human system. Second, the paper suggested that concerns of just compensation should be the primary focus of the WIM. With regard to these considerations, the paper proposed that there are good reasons why finding measures to most efficiently, effectively and fairly remedy L\&D is more significant than appropriately assigning corrective liabilities. Third, the paper recommended understanding climate damage as that impact which can be recovered in such a way that those affected can still pursue the same valued objectives as before L\&D occurred. Climate loss, on the other hand, is that impact which makes a transition of valued objectives necessary; this can mean a shift in the way livelihood and economic subsistence is secured, transition of cultural heritage, or even change in political organization.

The paper only hinted at possible justifications for and conclusions from the distinctions it proposed but did not elaborate them fully. Further normative justice research, in collaboration with other branches of climate-related research, can enable the international community to deliver concrete policy proposals. In the meantime, however, the paper hopefully helped delineate the contours of how the WIM and accompanying mechanisms should develop until the end of the review period in 2016, leading to a decision at COP 22.

Acknowledgments Earlier versions of this paper have been presented at the Annual Workshop of the UZH/ ETH Zurich Network for Interdisciplinary Climate Change Research held in 2013 and a workshop entitled "New Debates in Climate Change Justice, Governance and Democracy" at the University of Warwick in 2014. I would like to thank the audiences of both these occasions as well as Hajo Eicken, Axel Gosseries, Gerrit Hansen, Christian Huggel, Simon Milligan, Edward Page, Fabian Schuppert, Daithi Stone, three anonymous reviewers,

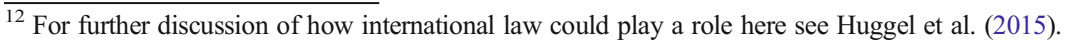


and especially Dominic Roser for very helpful and much needed comments, discussion and inspiration. I also would like to acknowledge the generous financial support of Stiftung Mercator Switzerland and the University of Zurich's Research Priority Program for Ethics (URPP Ethics), without which the research for this paper would not have been possible.

\section{References}

Bell DR (2004) Environmental refugees: what rights? Which duties? Res Publica 10:135-152

Blum G, Lockwood NJ (2012) Earthquakes and Wars: The Logic of International Reparations. Public Law \& Legal Theory Working Paper Series(12-30)

Bronen R (2013) Climate-Induced Displacement of Alaska Native Communities

Byravan S, Rajan SC (2010) The ethical implications of sea-level rise due to climate change. Ethics \& International Affairs 24(3):239-260

Caney S (2010) Climate change and the duties of the advantaged. Critical Review of International Social and Political Philosophy 13(1):203-228

Caney S (2012) Just emissions. Philosophy \& Public Affairs 40(4):255-300

de Shalit A (2011) Climate change refugees, compensation and rectification. Monist 94(3) 301-328

Dow K, Berkhout F, Preston BL, Klein RJ, Midgley G, Shaw MR (2013) Limits to adaption. Nat Clim Chang 3(April):305-307

Gardiner SM, Caney S, Jamieson D, Shue H (eds) (2010) Climate ethics: essential readings. Oxford University Press, Oxford, New York

Goodin RE (1989) Theories of compensation. Oxf J Leg Stud 9(1):56-75

Heyward C (2014) Climate Change as Cultural Injustice. In: Brooks T (ed) New Waves in Global Justice, pp 149-169

Huggel C, Stone D, Auffhammer M, Hansen G (2013) Loss and damage attribution. Nat Clim Chang 5(August): 694-696

Huggel C, Stone D, Eicken H, Hansen G (2015) Potential and limitations of the attribution of climate change impacts for informing loss and damage discussions and policies. Climatic Change:this issue

IPCC (2014) Climate Change 2014: Impacts, Adaptation, and Vulnerability: WG II AR5: Technical Summary

Meyer LH, Roser D (2010) Climate justice and historical emissions. Critical Review of International Social and Political Philosophy 13(1):229-253

Miller D (2007) National responsibility and global justice. Oxford University Press, Oxford

Nishat A, Mukherjee N, Roberts E, Hasemann A (2013) A range of approaches to address loss and damage from climate change impacts in Bangladesh. http://www.loss-and-damage.net/4825. Accessed 03 September 2014

Page E (2008) Distributing the burdens of climate change. Environmental Politics 17(4):556-575

Shue H (1999) Global environment and international inequality. Int Aff 75(3):531-545

Stone D, Auffhammer M, Carey M, Hansen G, Huggel C, Cramer W, Lobell D, Molau U, Solow A, Tibig L, Yohe G (2013) The challenge to detect and attribute effects of climate change on human and natural systems. Clim Chang 121(2):381-395

UNFCCC (2012) A literature review on the topics in the context of thematic area 2 of the work programme on loss and damage: a range of approaches to address loss and damage associated with the adverse effects of climate change, Doha

UNFCCC (2013) Non-Economic Losses: Technical Paper

UNFCCC (2014) Report of the Conference of the Parties on its nineteenth session, held in Warsaw from 11 to 23 November 2013: Part two: Action taken by the Conference of the Parties at its nineteenth session

Vanderheiden S (2009) Atmospheric justice: A political theory of climate change, 1st edn. Oxford Univ. Press, Oxford [u.a.]

Visser H, Petersen AC, Ligtvoet W (2014) On the relation between weather-related disaster impacts, vulnerability and climate change. Clim Chang 125(3-4):461-477

Warner K, van der Geest K (2013) Loss and damage from climate change: local-level evidence from nine vulnerable countries. International Journal of Global Warming 5(4):367-386

Wrathall D, Oliver-Smith A, Sakdapolrak P, Gencer E, Fekete A, Lepana Reyes M (2013) Conceptual and Operational Problems for Loss and Damage: Working Paper. http://www.populationenvironmentresearch. org/documents/Loss_and_Damage_2013.pdf. Accessed 03 September 2014

Zellentin A (2010) Climate migration: cultural aspects of climate change. Analyse \& Kritik 1:63-86 